\title{
Using rewards-based incentives to increase purchase of fruit and vegetables in lower-income households: design and start-up of a randomized trial
}

\author{
Etienne J Phipps ${ }^{1, *}$, Samantha L Wallace ${ }^{1}$, Shana D Stites ${ }^{1}$, Nadine Uplinger ${ }^{2}$, \\ S Brook Singletary ${ }^{1}$, Lacy Hunt ${ }^{3}$, Saul Axelrod ${ }^{4}$, Karen Glanz ${ }^{5}$ and Leonard E Braitman ${ }^{3}$ \\ ${ }^{1}$ Center for Urban Health Policy and Research, Einstein Healthcare Network, 5501 Old York Road, \\ Philadelphia, PA 19141, USA: ${ }^{2}$ Gutman Diabetes Institute, Einstein Healthcare Network, Philadelphia, PA, USA: \\ ${ }^{3}$ Office of Research and Technology Development, Einstein Healthcare Network, Philadelphia, PA, USA: \\ ${ }^{4}$ Special Education and Applied Behavior Analysis Programs, Temple University, Philadelphia, PA, USA: \\ ${ }^{5}$ Perelman School of Medicine and School of Nursing, University of Pennsylvania, Philadelphia, PA, USA
}

Submitted 11 April 2012: Final revision received 8 August 2012: Accepted 24 August 2012: First published online 20 November 2012

\begin{abstract}
Objective: To report the design and baseline results of a rewards-based incentive to promote purchase of fruit and vegetables by lower-income households.

Design: A four-phase randomized trial with wait-listed controls. In a pilot study, despite inadequate study coupon use, purchases of fresh fruit (but not vegetables) increased, but with little maintenance. In the present study, credits on the study store gift card replace paper coupons and a tapering phase is added. The primary outcome is the number of servings of fresh and frozen fruit and vegetables purchased per week.

Setting: A large full-service supermarket located in a predominantly minority community in Philadelphia, Pennsylvania, USA.

Subjects: Fifty-eight households, with at least one child living in the home.

Results: During the baseline period, households purchased an average of 3.7 servings of fresh vegetables and an average of less than 1 serving of frozen vegetables per week. Households purchased an average of 1.9 servings of fresh fruit per week, with little to no frozen fruit purchases. Overall, the range of fresh and frozen produce purchased during this pre-intervention period was limited. Conclusions: At baseline, produce purchases were small and of limited variety. The study will contribute to understanding the impact of financial incentives on increasing the purchases of healthier foods by lower-income populations.
\end{abstract}

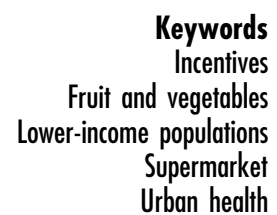

Only an estimated $26 \%$ of Americans consume the recommended daily servings of vegetables and $33 \%$ consume the suggested amount of fruit ${ }^{(1)}$. Close to $20 \%$ of lower-income households in the USA do not purchase fruit and vegetables at all ${ }^{(2)}$. These households may use their limited financial resources to purchase less expensive energy-dense processed foods over more expensive healthier foods ${ }^{(3-5)}$. In order to make healthier foods more affordable, financial incentives - in the form of vouchers or additional subsidies - are currently being used to promote purchases by lower-income populations $^{(6,7)}$. Whether or not these strategies will be successful in increasing purchase of healthier foods is not yet known.

The use of financial incentives to motivate behaviour is not without controversy ${ }^{(8-10)}$. Some argue that providing payment for behaviour reflects a power imbalance between those offering and those receiving ${ }^{(11)}$. Common criticisms of incentives are that any changes in behaviour are likely to be short lived and not sustainable once the incentive is stopped. Research using financial incentives to motivate healthy behaviours is a relatively new area of research. Short-term successes have been reported in rates of smoking cessation ${ }^{(12)}$, achieving weight loss ${ }^{(13)}$ and improving medication adherence ${ }^{(14)}$. However, many questions about longer-term impact remain.

In the present paper we report on the design and baseline results of the Frequent Buyer Rewards Study (hereafter referred to as the 'Rewards Study'). The study investigates the use of a rewards-based intervention to promote purchase of fresh and frozen fruit and vegetables by lower-income households. The conceptual framework is an ecological model of a 'community nutritional environment ${ }^{(15,16)}$. Eating patterns are understood to be influenced by individual characteristics, environmental factors associated with food availability, as well as by government and industry policies. Economic incentives 
are hypothesized to facilitate changes towards more healthful purchases by decreasing the individual-level impediment associated with economic hardship or poverty. To understand the use of incentives in health behaviour change, we draw on concepts from behavioural economics and psychology. Structuring options and providing prompts are strategies to direct individuals to behave differently ${ }^{(17,18)}$. Measurable, tangible benefits are used to make it easier and more appealing to adopt healthier practices ${ }^{(14,19)}$. Practical skill building around food selection and preparation and ongoing feedback promote engagement, enhance self-efficacy ${ }^{(20)}$ and build the confidence needed to promote longer-term maintenance. The primary research question is whether a rewards-based incentive combined with practical nutritional information and ongoing feedback and support results in households increasing their purchases of fresh and frozen produce.

\section{Methods}

\section{Pilot study}

In 2010 we conducted a 12-week pilot study with twentynine participants to inform the design of the Rewards Study. The pilot consisted of a three-phase design: minimum 4-week retrospective baseline, 4-week intervention and 4-week follow-up. The pilot tested the use of coupons as incentives to buy fresh fruit and vegetables. We found that fresh produce increased from baseline to intervention, but not after the coupons were discontinued. We also determined that about $30 \%$ of participants had not shopped during the intervention phase because our inclusion criteria were not stringent enough. As a result, we made the following changes to the protocol. We added a shopping history verification procedure so that we could enroll participants who would be more likely to shop throughout the study periods. A tapering phase was added to the design to increase the likelihood of maintaining change after the incentive had been stopped. The incentive itself was modified; a rewards-based model of building points through purchases replaced the immediate purchase discount. Points towards rewards would be recorded when the participant swiped his/her store loyalty card at the time of purchase. Both these latter modifications were done with the hope of increasing use of the incentive and eliminating problems that had occurred with the paper coupons.

\section{Design of the Rewards Study}

The Rewards Study is a four-phase randomized trial designed to evaluate whether a rewards-based incentive increases the purchase of fruits and vegetables in lowincome households. The phases include: (i) a baseline purchase history of at least 8 weeks; (ii) an 8 -week active intervention; (iii) a 4 -week tapering of the intervention; and (iv) a 6-week follow-up (without any intervention). The study uses wait-listed controls, also known as a delayed treatment group. Wait-listed controls have a longer baseline period (serving as controls) and enter the intervention period eight weeks after the first group. The use of a wait-listed control group affords all participants the opportunity to benefit from the incentive, while also allowing for a randomized contemporaneous comparison. The primary outcome is the number of servings of fresh and frozen fruit and vegetables purchased.

Participants earn rewards when they purchase fresh or frozen fruit and vegetables at the study supermarket. A fruit and vegetable reference file of over 3200 fresh and frozen produce was built to track and analyse purchases. Produce items eligible for reward points were those defined by the Supplemental Nutrition Program for Women, Infants, and Children (WIC) guidelines for fresh and frozen produce ${ }^{(21)}$. Fresh white and red potatoes were added as study qualified items. Frozen fried white or sweet potatoes were excluded. Canned fruit and vegetables were not included because of time and resource limitations.

Participants are required to have a supermarket loyalty card so that the investigators can track participants' purchases and reward points. Reward credits in the form of dollars and cents are loaded onto a supermarket gift card that is provided to all participants at study onset. Reward credits may be used to purchase any item in the store. During the intervention phase, for every dollar spent on study-eligible fresh or frozen produce, participants receive fifty cents on their gift card. During the tapering phase, they will need to spend twice that amount (two dollars) to have fifty cents added to their gift card. The follow-up phase will not include any financial or other incentive. Participants' grocery receipts will display the amount spent that is eligible for rewards. Four study newsletters containing nutritional information, tips on selecting produce and easy recipes will be sent to participants at predetermined times during the intervention and tapering phases.

\section{Setting}

The Fresh Grocer supermarket is a large (50000 square feet) independently owned full-service grocery store situated in a retail shopping centre. One of a chain of eight supermarkets, this Fresh Grocer opened in 2009 supported by a unique state-wide programme, the Pennsylvania Fresh Food Financing Initiative (PFFFI). The PFFFI provides financing to supermarket operators who plan to open stores in underserved areas. The study store averages 10000 transactions weekly. According to 2010 census data, the census tract in which the store is located has a racial composition of $89 \cdot 1 \%$ African Americans, $6 \cdot 6 \%$ whites and $4 \cdot 3 \%$ all others. Hispanics or Latinos of any race constitute $3 \cdot 0 \%$ of the population within the census tract. Most of the store shoppers reside in that area. 


\section{Eligibility}

Eligible participants were adult men and women, primary shoppers for a household with at least one child in the home full-time, with an annual household income of \$US 60000 or less. Additional criteria included having a store loyalty card, a minimum 8-week history of shopping at the study store and shopping at least three times during that 8 -week period. They had to do at least half of their household grocery shopping and buy at least half or their fresh and frozen produce at the study store (by self-report).

\section{Recruitment}

Recruitment targeted participants who used the supermarket for most of their household grocery shopping. First, the marketing director sent out letters ( $n$ 239) to customers who had the highest weekly expenditures at that store informing them of the study and asking them to contact our research office should they be interested in participating in the study. However, three weeks after the mailing was sent out, only eight customers had contacted our office, and only two met the household income criteria. Based on the low yield of this approach, we initiated in-store recruitment.

The recruiters (S.L.W., S.B.S.) were positioned at the store entrance, which leads customers directly into the produce section of the store. This allowed the recruiters to interact with customers while they were in the produce section. The recruiters talked about the study and provided study materials to interested shoppers. In addition, store check-out personnel received a brief study orientation and were provided 'bag stuffers' with study information that they placed in customers' shopping bags. There was no separate recruitment for wait-listed controls.

\section{Enrolment}

Participants who met the inclusion criteria were informed in more detail about the study either on-site or by telephone, including the need to verify shopping history at the store before final confirmation of enrolment. If they agreed to have their shopping transactions available to the study team and to other study procedures, in-person or telephone consent was obtained. Participants were asked to provide registration numbers of all study store loyalty cards used by members of the household so that we could best track household purchases.

Interviews were conducted with consenting participants to collect individual and household information. This included: participant age, gender, ethnicity, education, employment status, number of people living in the home, ages of all children in the home, annual household income, and enrolment status in the Supplemental Nutrition Assistance Program (SNAP) and WIC. Once shopping history was verified, which required one to two weeks for store personnel to retrieve trans- actions and send to the research office, participants were randomized.

Randomization was conducted using a computer program that assigned a participant to one of the two treatment groups ('intervention' or 'wait-listed control'). Randomization resulted in 52\% ( $n$ 30) of participants assigned to the intervention group and $48 \%$ ( $n$ 28) to the wait-listed control group. Participant flow from eligibility through randomization is shown in Fig. 1.

\section{Data management}

Baseline shopping data were obtained to establish shopping history at the study store. Recruitment for the study began on 24 January 2011 and ended on 22 April 2011. In order to make data extraction less cumbersome for the store data analyst, store transactions for all potential participants were retrieved back to a fixed date (1 December 2010). The amount of fresh and frozen fruit and vegetables purchased per week by study participant households at baseline was assessed by the number of adult servings, number of cups and gross dollar cost.

Adult serving sizes were calculated based on the Food Buying Guide for Child Nutrition Programs ${ }^{(22)}$ of the US Department of Agriculture (USDA). To derive the number of adult servings, the number of USDA (child) servings was divided by 2 or 4 , depending on the standard portion size of the specific produce item ${ }^{(23,24)}$. The number of cups of fruit and vegetables purchased per week was the number of $8 \mathrm{oz}$ volume units. For items sold by weight or count rather than volume, USDA estimates of mass and density were used to convert all item amounts to volume ${ }^{(25)}$. The cost of purchased items was the full cost of produce paid with cash or cash equivalents. Produce that was not identified (unclassified items) in the transaction data except by price was not included in these analyses.

\section{Statistical analysis}

Descriptive statistics and Fisher's exact test of proportions were used to describe and compare households randomly assigned to the intervention and wait-listed control groups. The amounts of fruit and vegetables purchased per week in households in each of the two treatment conditions were compared using unpaired $t$ tests allowing for unequal variances. Because the differences were not always normally distributed, the $P$ values reported were from bias-corrected and accelerated confidence intervals constructed using 1000 bootstrap resamples. All statistical tests were two-sided and $P$ values less than 0.05 were considered statistically significant. Statistical analyses were performed using the statistical software packages SAS version $8 \cdot 2$ and PASW Statistics version $18 \cdot 0$.

\section{Ethical approval}

The study was approved by the Institutional Review Board of the Einstein Healthcare Network. 


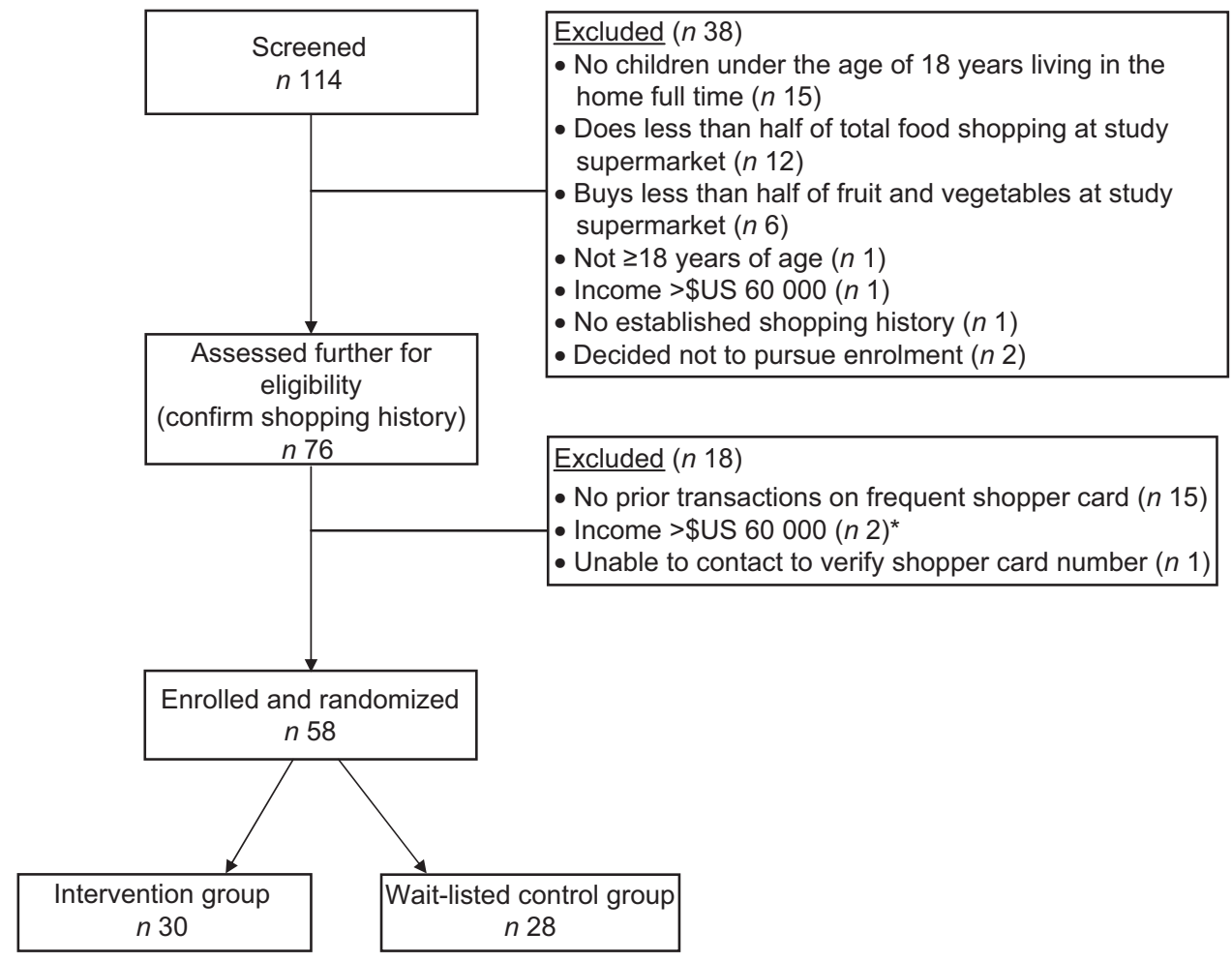

Fig. 1 Flow of participant recruitment from screening to randomization (*income exclusion was not identified during screening, but addressed during further assessment for eligibility)

\section{Baseline results}

\section{Participant recruitment}

Fifty-eight participants were recruited within an allotted 3 -month period. The majority ( $81 \%$ ) were recruited as a result of reading study information placed in shopping bags ('bag stuffers'). Other recruitment strategies had a more modest yield: mailed letters (10\%) and on-site recruitment by researchers (7\%). One caller heard about the study from a friend.

\section{Baseline characteristics}

Participant characteristics overall and by group assignment are shown in Table 1. Most participants were African American (95\%) and female (81\%). The average age was $50 \cdot 4$ years. The average household size was 3.8 persons with an average of 1.7 children in the household. Sixty-nine per cent of participants reported an annual household income of \$US 25000 or less. Sixty-two per cent were enrolled in SNAP and 29\% in WIC. More participants in the wait-listed control group were enrolled in WIC than those in the intervention group ( $43 \% v .17 \% ; P=0.043$ ). There were no other apparent differences in participant or household characteristics by study group assignment.

\section{Baseline phase purchases}

The average weekly amounts of fresh and frozen fruit and vegetables purchased in the intervention and wait-listed control groups were similar (all $P>0 \cdot 05$, Table 2). Overall, fresh potatoes, onions, tomatoes, lettuce, salad mixes and greens were the fresh vegetables purchased most frequently at baseline, in that order. The most frequently purchased frozen vegetables were broccoli, mixed vegetables, green beans and corn (data not shown). The intervention group purchased an average of 3.99 servings of fresh vegetables per week and the control group purchased an average of $3 \cdot 28$.

Bananas, grapes, oranges, apples and strawberries were the most frequently purchased fresh fruit, in that order. Frozen fruit (i.e. frozen strawberries) was purchased only twice during this period. At baseline, households in the intervention group purchased an average of 1.47 servings/week and households in the control group purchased $2 \cdot 37$ servings/week.

\section{Discussion}

The Rewards Study tests a rewards-based incentive programme during four phases (baseline, intervention, tapering and follow-up). Results of the pilot study improved the design and methods of the Rewards Study by strengthening the eligibility criteria and adding a tapering phase to the protocol to allow more time for participants to adjust to their improved purchase patterns without the benefit of an incentive. 
Table 1 Characteristics of participants

\begin{tabular}{|c|c|c|c|c|c|c|}
\hline \multirow[b]{2}{*}{ Variable } & \multicolumn{2}{|c|}{$\begin{array}{l}\text { Full study group } \\
\qquad(n 58)\end{array}$} & \multicolumn{2}{|c|}{$\begin{array}{c}\text { Intervention group } \\
(n 30)\end{array}$} & \multicolumn{2}{|c|}{$\begin{array}{l}\text { Wait-listed control group } \\
(n 28)\end{array}$} \\
\hline & Mean & SD & Mean & SD & Mean & SD \\
\hline Age (years) & $50 \cdot 4$ & $13 \cdot 2$ & $53 \cdot 4$ & $13 \cdot 0$ & $47 \cdot 1$ & $12 \cdot 7$ \\
\hline Household size & $3 \cdot 8$ & $1 \cdot 4$ & $3 \cdot 7$ & $1 \cdot 3$ & $3 \cdot 9$ & 1.5 \\
\hline \multirow[t]{2}{*}{ Number of children in household } & $1 \cdot 7$ & $1 \cdot 0$ & $1 \cdot 5$ & $0 \cdot 7$ & $1 \cdot 9$ & $1 \cdot 3$ \\
\hline & $n$ & $\%$ & $n$ & $\%$ & $n$ & $\%$ \\
\hline Female & 47 & $81 \cdot 0$ & 26 & $86 \cdot 7$ & 21 & $75 \cdot 0$ \\
\hline \multicolumn{7}{|l|}{ Race/ethnicity† } \\
\hline African American & 55 & $94 \cdot 8$ & 29 & $96 \cdot 7$ & 26 & $92 \cdot 9$ \\
\hline White (not of Hispanic origin) & 1 & $1 \cdot 7$ & 1 & $3 \cdot 3$ & 0 & 0.0 \\
\hline Hispanic/Latino & 1 & $1 \cdot 7$ & 0 & 0.0 & 1 & $3 \cdot 6$ \\
\hline \multicolumn{7}{|l|}{ Marital status } \\
\hline Married/living with partner & 20 & $34 \cdot 5$ & 9 & $30 \cdot 0$ & 11 & $39 \cdot 2$ \\
\hline Single/never married & 18 & $31 \cdot 0$ & 10 & $33 \cdot 3$ & 8 & $28 \cdot 6$ \\
\hline Divorced/separated & 11 & $19 \cdot 0$ & 4 & $13 \cdot 3$ & 7 & $25 \cdot 0$ \\
\hline Widowed & 9 & $15 \cdot 5$ & 7 & $23 \cdot 4$ & 2 & $7 \cdot 2$ \\
\hline \multicolumn{7}{|l|}{ Education } \\
\hline$\leqslant 12$ years of education & 28 & $48 \cdot 3$ & 16 & $53 \cdot 3$ & 12 & $42 \cdot 9$ \\
\hline$>12$ years of education & 30 & $51 \cdot 7$ & 14 & $46 \cdot 7$ & 16 & $57 \cdot 1$ \\
\hline \multicolumn{7}{|l|}{ Annual household incomet } \\
\hline$<\$$ US 25000 & 40 & $69 \cdot 0$ & 21 & $70 \cdot 0$ & 19 & $67 \cdot 9$ \\
\hline \$US 25001-50000 & 14 & $24 \cdot 1$ & 7 & $23 \cdot 3$ & 7 & $25 \cdot 0$ \\
\hline$>$ \$US 50000 & 2 & 3.4 & 0 & 0.0 & 2 & $7 \cdot 2$ \\
\hline SNAP enrolled & 36 & $62 \cdot 1$ & 20 & $66 \cdot 7$ & 16 & $57 \cdot 1$ \\
\hline WIC enrolled* & 17 & $29 \cdot 3$ & 5 & $16 \cdot 7$ & 12 & $42 \cdot 9$ \\
\hline
\end{tabular}

SNAP, Supplemental Nutrition Assistance Program; WIC, Supplemental Nutrition Program for Women, Infants, and Children.

${ }^{*}$ Significantly more participants in the wait-listed control group were enrolled in WIC than those in the intervention group $(P=0.043)$.

tTotal does not sum to $100 \%$ because some participants chose not to answer the question.

Table 2 Baseline average weekly fruit and vegetable purchases by group assignment

\begin{tabular}{|c|c|c|c|c|c|c|}
\hline & \multicolumn{2}{|c|}{$\begin{array}{l}\text { Full study group } \\
\qquad(n 57) \dagger\end{array}$} & \multicolumn{2}{|c|}{$\begin{array}{l}\text { Intervention group } \\
\qquad(n 30)\end{array}$} & \multicolumn{2}{|c|}{$\begin{array}{l}\text { Wait-listed control group } \\
(n 27)\end{array}$} \\
\hline & Mean & SD & Mean* & SD & Mean* & SD \\
\hline \multicolumn{7}{|c|}{ Fresh and frozen fruit and vegetables } \\
\hline Servings/week & $6 \cdot 36$ & $6 \cdot 44$ & $6 \cdot 46$ & $6 \cdot 81$ & $6 \cdot 25$ & $6 \cdot 13$ \\
\hline Cups/weekł & $4 \cdot 23$ & $4 \cdot 49$ & $4 \cdot 27$ & $4 \cdot 80$ & $4 \cdot 19$ & $4 \cdot 19$ \\
\hline Dollars/week & $2 \cdot 15$ & $2 \cdot 37$ & $2 \cdot 12$ & $2 \cdot 08$ & $2 \cdot 18$ & $2 \cdot 67$ \\
\hline \multicolumn{7}{|l|}{ Fresh vegetables } \\
\hline Servings/week & $3 \cdot 65$ & $4 \cdot 06$ & $3 \cdot 99$ & $4 \cdot 95$ & $3 \cdot 28$ & $2 \cdot 80$ \\
\hline Cups/week‡ & $2 \cdot 38$ & $2 \cdot 87$ & $2 \cdot 64$ & $3 \cdot 58$ & $2 \cdot 09$ & $1 \cdot 81$ \\
\hline Dollars/week & 0.95 & $1 \cdot 04$ & $1 \cdot 03$ & $1 \cdot 24$ & $0 \cdot 85$ & 0.78 \\
\hline \multicolumn{7}{|l|}{ Frozen vegetables } \\
\hline Servings/week & $0 \cdot 79$ & $1 \cdot 29$ & 0.97 & $1 \cdot 43$ & 0.60 & $1 \cdot 13$ \\
\hline Cups/week $\ddagger$ & $0 \cdot 40$ & $0 \cdot 65$ & $0 \cdot 48$ & $0 \cdot 71$ & $0 \cdot 30$ & 0.56 \\
\hline Dollars/week & $0 \cdot 36$ & 0.56 & 0.41 & 0.59 & 0.29 & 0.53 \\
\hline \multicolumn{7}{|l|}{ Fresh fruit } \\
\hline Servings/week & $1 \cdot 89$ & $3 \cdot 30$ & $1 \cdot 47$ & $1 \cdot 63$ & $2 \cdot 37$ & $4 \cdot 48$ \\
\hline Cups/weekł & $1 \cdot 44$ & $2 \cdot 34$ & $1 \cdot 12$ & $1 \cdot 28$ & $1 \cdot 80$ & $3 \cdot 12$ \\
\hline Dollars/week & 0.83 & $1 \cdot 42$ & 0.65 & 0.73 & $1 \cdot 04$ & 1.91 \\
\hline \multicolumn{7}{|l|}{ Frozen fruit } \\
\hline Servings/week & 0.02 & $0 \cdot 12$ & 0.03 & $0 \cdot 17$ & 0 & 0 \\
\hline Cups/week $\ddagger$ & 0.01 & 0.06 & 0.02 & 0.08 & 0 & 0 \\
\hline Dollars/week & 0.01 & $0 \cdot 11$ & 0.03 & $0 \cdot 15$ & 0 & 0 \\
\hline
\end{tabular}

*Mean weekly amounts of fresh and frozen fruit and vegetables purchased in the intervention and wait-listed control groups were similar $(P \geq 0 \cdot 32)$.

tThe total number of participants listed is fifty-seven, not fifty-eight, because a decision was made by the Principal Investigator to enrol one participant in the study who had recently moved to the area. She met all other inclusion criteria.

‡Based on 8 oz cup size.

The baseline data of the Rewards Study indicate that participants purchased only a limited amount and selection of fresh and frozen produce. In addition, we found no apparent differences in sociodemographic characteristics or in average weekly purchases between the intervention and control groups. These results establish a solid baseline cohort from which we can make comparisons in the remaining three phases of the study. 
The Rewards Study will identify the potential impact of providing a financial incentive to promote purchase of fresh and frozen produce in the short term and in the longer term. Incentives combined with practical information about food selection and preparation may help increase consumption of these foods and change how individuals think about the connection of food with health.

\section{Acknowledgements}

Source of funding: This work was supported by The Robert Wood Johnson Foundation (grant \#68246, Principal Investigator: E.J.P.). Conflicts of interest: The authors have no conflicts of interest. Authors' contributions: E.J.P. was responsible for design and implementation of the study, contributed to interpretation of the results and led the writing of the article. S.L.W. conducted interviews, assisted in management and analysis of the data and participated in manuscript preparation. S.D.S. was a major contributor to the study design, was responsible for data management procedures and conducted the analyses. N.U. provided nutritional expertise in the design and ongoing stages of the study and participated in the writing of the manuscript. S.B.S. interviewed participants, assisted in the data management and analyses and participated in manuscript preparation. L.H. assisted in the data analysis and manuscript preparation. S.A. contributed to the study design and participated in the data interpretation and manuscript preparation. K.G. contributed to the study design and participated in the data interpretation and manuscript preparation. L.E.B. was a major contributor to the study design and led the statistical analyses and interpretation of results. All authors were involved in the writing of the article. Acknowledgements: The authors thank Fresh Grocer staff, especially Carly Spross and Glenn Foster, for their assistance in this study.

\section{References}

1. Grimm K, Blanck H, Scanlon K et al. (2010) State-specific trends in fruit and vegetable consumption among adults United States, 2000-2009. MMWR Morb Mortal Wkly Rep 59, $1125-1130$.

2. Blisard N, Stewart H \& Jolliffe D (2004) Low-Income Households' Expenditures on Fruits and Vegetables. Agricultural Economic Report no. 833. Washington, DC: USDA.

3. Drewnowski A (2003) Fat and sugar: an economic analysis. $J$ Nutr 133, issue 3, 8385-840S.

4. Drewnowski A \& Darmon N (2005) Food choices and diet costs: an economic analysis. J Nutr 135, 900-904.

5. Powell LM, Han E \& Chaloupka FJ (2010) Economic contextual factors, food consumption, and obesity among US adolescents. J Nutr 140, 1175-1180.
6. US Department of Agriculture (2007) Special Supplemental Nutrition Program for Women, Infants, and Children (WIC): Revisions in the WIC Food Packages Interim Rule. Alexandria, VA: USDA; available at http://www.fns.usda.gov/ wic/regspublished/wicfoodpkginterimrulepdf.pdf.

7. Brown K (2008) Food Stamp Program: Options for Delivering Financial Incentives to Participants for Purchasing Targeting Foods. GAO no. 08-415. Washington, DC: Government Accountability Office.

8. Marteau T, Ashcroft R \& Oliver A (2009) Using financial incentives to achieve healthy behaviour. BMJ 338, 983-985.

9. Pink DH (2009) Drive: The Surprising Truth About What Motivates Us, 1st ed. New York: Riverhead Books.

10. Kamenica E (2011) Behavioral economics and psychology of incentives. PhD Thesis, University of Chicago Booth School of Business.

11. Grant RW (2011) Strings Attached: Untangling the Ethics of Incentives, 1st ed. Princeton, NJ: Princeton University Press.

12. Volpp KG, Levy AG, Asch DA et al. (2006) A randomized controlled trial of financial incentives for smoking cessation. Cancer Epidemiol Biomarkers Prev 15, 12-18.

13. Volpp KG, John LK \& Troxel AB (2008) Financial incentive based approaches for weight loss: a randomized trial. JAMA 300, 2631-2637.

14. Loewenstein G, Brennan T \& Volpp KG (2007) Assymmetric paternalism to improve health behaviors. JAMA $\mathbf{2 9 8}$, 2415-2417.

15. Glanz K, Sallis JF, Saelens BE et al. (2005) Healthy nutrition environments: concepts and measures. Am J Health Promot 19, 330-333.

16. Sallis J \& Glanz K (2009) Physical activity and food environments: solutions to the obesity epidemic. Milbank Q 87, 123-154.

17. Thaler RH \& Sunstein CR (2008) Nudge: Improving Decisions about Health, Wealth, and Happiness, 10th ed. New York: Penguin Books.

18. Schwartz H (2008) A Guide to Behavioral Economics, 1st ed. Falls Church, VA: Higher Education Publications.

19. Halpern SD, Ubel PA \& Asch DA (2007) Harnessing the power of default options to improve health care. NEngJ Med 357, 1340-1344.

20. Bandura A (1986) Social Foundations of Thought and Action: A Social Cognitive Theory, 1st ed. Englewood Cliffs, NJ: Prentice-Hall.

21. US Department of Agriculture (2012) WIC food packages regulatory requirements of WIC-eligible foods: fruits and vegetables. http://www.fns.usda.gov/wic/benefitsandservices/ foodpkgregs.HTM\#FRUITS_and_VEGETABLES (accessed March 2012).

22. US Department of Agriculture (2007) Food buying guide for child nutrition programs. http://www.fns.usda.gov/tn/ resources/FBG_Index.pdf (accessed March 2012).

23. US Department of Agriculture (2010) What counts as a cup of vegetables? http://www.mypyramid.gov/pyramid/ vegetables_counts.html (accessed March 2012).

24. US Department of Agriculture (2010) What counts as a cup of fruit? http://www.mypyramid.gov/pyramid/fruits_counts.html (accessed March 2012).

25. US Department of Agriculture (2011) USDA National Nutrient Database for Standard Reference. http://www.nal. usda.gov/fnic/foodcomp/search/ (accessed March 2012). 